\title{
Total Fluoride Intake and Urinary Excretion in German Children Aged 3-6 Years
}

\author{
$\begin{array}{llll}\text { M. Haftenberger a } & \text { G. Viergutz } & \text { V. Neumeister } & \text { G. Hetzera }\end{array}$ \\ a Department of Paediatric Dentistry, ${ }^{b}$ Institute of Clinical Chemistry and Laboratory Medicine, Faculty of \\ Medicine, University of Technology, Dresden, Germany
}

\section{Key Words}

Children $\cdot$ Fluoride intake $\cdot$ Urinary fluoride excretion

\begin{abstract}
There have only been few investigations comparing total fluoride intake and the fluoride proportion excreted in urine in pre-school children. In addition, the results of available studies are conflicting. Total fluoride intake was assessed in 11 healthy children aged 3-6 years on 2 consecutive days and urinary fluoride excretion was determined. The duplicate-diet approach was used for the assessment of fluoride intake from solid and liquid foods. Fluoride intake from toothbrushing was calculated as the difference between the amount of fluoride in the paste put on the toothbrush and the drinking water (fluoride concentration $0.25 \mathrm{mg} / \mathrm{l}$ ) used for rinsing vs. the fluoride amounts recovered in the toothpaste spat out and in the rinsing water. Use of fluoridated domestic salt and/or fluoride tablets was recorded. The children's intake of fluoride from food averaged 202.5 \pm $116.2 \mu \mathrm{g} \mathrm{F} /$ day. They swallowed an average amount of $273.9 \pm 175.6 \mu \mathrm{g} \mathrm{F} /$ day when brushing their teeth. Daily fluoride ingestion from all sources totalled $930.7 \pm$ $391.5 \mu \mathrm{g}$ or $53.0 \pm 21.4 \mu \mathrm{g} / \mathrm{kg}$ body weight. On average $51.5 \%$ of the fluoride ingested was excreted in urine. The wide interindividual variation makes it necessary to evaluate the urinary excretion rate for fluoride in larger study populations with varied fluoride exposure.
\end{abstract}

Copyright (C) 2001 S. Karger AG, Basel (c) 2001 S. Karger AG, Basel

0008-6568/01/0356-0451 \$17.50/0

Fax +41613061234

E-Mail karger@karger.ch

www.karger.com
Accessible online at: www.karger.com/journals/cre
Monitoring the fluoride intake of small children and preschoolers is of special significance. In that age bracket excessive fluoride ingestion may result in aesthetically objectionable enamel fluorosis in permanent teeth. Fluoride exposure during mineralisation of the permanent teeth should be designed to provide a caries-preventing effect while avoiding dental fluorosis of an undesirable extent. The range of $0.05-0.07 \mathrm{mg}$ of fluoride $(\mathrm{F}) / \mathrm{kg}$ body weight (b.w.) is usually regarded as the so-called 'optimum' amount of daily fluoride intake [Burt, 1992]. Whitford et al. [1987] consider an upper limit of $0.1 \mathrm{mg} \mathrm{F} / \mathrm{kg}$ b.w. acceptable.

Exact assessment of daily total fluoride intake is difficult. Apart from solid and liquid foods which include drinking water and mineral water, determination of total intake nowadays needs to consider fluoride supplements, toothpaste and other preparations used for caries prevention. There are only few investigations into the fluoride intake of small children and pre-school children that include all these sources [Guha-Chowdhury et al., 1996; Rojas-Sanchez et al., 1999; Villa et al., 2000; Zohouri and Rugg-Gunn, 2000].

In the available studies, determinations of fluoride intake were either based on dietary records of the amounts and nature of the food ingested and subsequent calculation of fluoride content available in food consumption tables [Fomon and Ekstrand, 1993] or they were assessed on the basis of the duplicate-diet method [Guha-Chowdhury et al., 1996; Rojas-Sanchez et al., 1999]. The latter approach is usually favoured because it permits analysis of the food actually ingested and precludes potential sources of error like inaccu-

Prof. Dr. Gisela Hetzer

Department of Paediatric Dentistry

University of Technology

Fetscherstrasse 74, D-01307 Dresden (Germany)

Tel. ++49 351/458 2714, Fax++49 351/458 5303, E-Mail g.hetzer@ rcz.urz.tu-dresden.de 
rate recording of amounts, inadequate coding, or non-inclusion of a given food type in the food consumption table [Birkhed, 1990].

Measuring the fluoride excreted in urine [Rugg-Gunn et al., 1993; Marthaler et al., 1995, 2000] is another well-established method of assessing fluoride exposure of a population or of quantifying the daily fluoride intake in children. Based on older studies, it was assumed that under stable fluoride exposure urinary fluoride excretion was about $50 \%$ of the intake in adults and 30\% in children [Murray et al., 1991]. Pertinent evaluations of fluoride balance, i. e. the relationship of fluoride intake vs. fluoride excretion in small children and pre-schoolers, have been relatively scarce and results were conflicting. While in their studies of children 3-5 years of age, Villa et al. [2000] found that the rate of urinary fluoride excretion averaged $35.5 \%$ of the amount ingested, the investigations of Brunetti and Newbrun [1983] and Zohouri and Rugg-Gunn [2000] in pre-school children indicated considerably higher urinary excretion rates of $80-85 \%$.

In view of these conflicting results the present study was designed: (a) to determine the total fluoride intake of healthy pre-school children in a region with low fluoridation of drinking water (FDW); (b) to determine the amount of fluoride excreted in urine within $24 \mathrm{~h}$, and (c) to assess the statistical relation between fluoride intake and excretion.

\section{Participants and Methods}

\section{Participants}

Eleven healthy children, 6 boys and 5 girls aged 3-6 years, participated in the study in autumn 1998. Residence at the place of the investigation, i. e. Dresden, for 2 years prior to the beginning of the study was a prerequisite for participation. Fluoride content of the community drinking water is $0.25 \mathrm{mg} / \mathrm{l}$. Fluoride supplementation is a tradition of long standing in this region. Very high parent compliance was an important criterion for the inclusion of a child. The body weights of all children were determined on admission to the study. The study period comprised 2 consecutive days on a weekend. Regular habits as regards the children's diets, toothbrushing, administration of fluoride tablets or use of fluoridated domestic salt were to be kept up for the time of the study.

\section{Collection of Solid Food and Beverages}

The determination of dietary fluoride intake relied on the duplicate-diet approach. Parents were given detailed written instructions for the proper collection of all duplicate portions, including snacks, sweets, beverages and foods eaten outside home between the main meals. In addition individual consultation made sure that the practicalities of participation were discussed with them in a step-by-step fashion. Parents were given three plastic containers for each study day, permitting them to collect separately identical portions of all sol- id foods, beverages excluding milk drinks and of milk or dairy products matching those consumed by the child. Food parts that had not been swallowed like bones or pits were to be removed from the mirror portions. Collection had to be repeated if a child was sick on a study day or if his/her diet was unusual.

The procedure allowed analysis of a total of six food mixes from each child. Solid food and dairy products were weighed after completing collection. The mixtures were homogenised by shaking (beverages and dairy products) or mashing (solid food), and $10 \mathrm{ml}$ each of the drinks and the dairy products as well as $100 \mathrm{~g}$ of solid food were freeze-dried for chemical analysis.

For validation of the duplicate collection parents were requested to keep a dietary record for the time of study, and to record meticulously and completely all products consumed, entering the exact amounts and preparation of foods. Common household measures, such as one tablespoon, one teaspoon or one cup, were acceptable. The dietary diaries were examined in the presence of the parents when they returned them in order to be able to identify products that had been listed but might be unknown to the investigator. The use of fluoridated domestic salt and/or supplementation by fluoride tablets also had to be entered in the dietary record. Parents were remunerated in appreciation of their help.

\section{Assessment of Fluoride Intake from Toothbrushing}

Parents recorded the frequency of toothbrushing and the brand of the toothpaste in the dietary diary. One member of the research team (M.H.) weighed at the participants' homes the amount of toothpaste and drinking water typically used for toothbrushing and collected the toothpaste slurry and rinsing liquid spat out by the child after brushing his/her teeth. The toothbrush with adhering toothpaste was thoroughly rinsed with the rest of drinking water used for brushing. All rinses were kept for fluoride analysis. Fluoride intake from toothbrushing was estimated as the difference between the amount of fluoride in the toothpaste plus that in the drinking water used for rinsing mouth and toothbrush on the one hand and the fluoride amount recovered in the toothpaste slurry spat out plus the rinsing liquids on the other. Calculations were based on the manufacturer's label claim for the fluoride concentration in the toothpaste used.

\section{Collection of 24-Hour Urine}

Urine samples and duplicate portions were collected during the same 24-hour periods. The children used potties for urination. The urine obtained was collected in a 1.5-litre plastic container with screw-cap closure separately for the first and second 24-hour periods. The urine volumes of both days were measured and one 10-ml sample each was frozen for fluoride analysis. Fluoride elimination via the faeces and sweat was not assessed.

\section{Fluoride Analysis}

All fluoride determinations were carried out using an ionometer (Radiometer, Copenhagen, Denmark) equipped with a fluoride-specific electrode, Model 50262 Combination Fluoride Electrode (HACH, Loveland, Colo., USA). The food samples were decomposed thermally. All the other samples (centrifuged urine samples, the spitmixture of toothpaste, rinsing liquid and the beverages without milk) were subjected directly to the fluoride analysis. The procedure for food decomposition was the following: After exact weighing of the food samples from each child (about $5 \mathrm{~g}$ each of homogenised solid food and dairy products) they were lyophilised for 3 days to stable weight. To 1-gram aliquots of the lyophilisate was added $0.5 \mathrm{ml}$ of 1 $\mathrm{N}$ sodium acetate solution (or parts) and subsequently incinerated us- 
Table 1. Age, gender, body weight and individual fluoride exposure in 11 pre-school children

\begin{tabular}{|c|c|c|c|c|c|c|}
\hline \multirow{2}{*}{$\begin{array}{l}\text { Child } \\
\text { No. }\end{array}$} & \multirow[t]{2}{*}{ Gender } & \multirow{2}{*}{$\begin{array}{l}\text { Age } \\
\text { years }\end{array}$} & \multirow{2}{*}{$\begin{array}{l}\text { Body } \\
\text { weight } \\
\mathrm{kg}\end{array}$} & \multicolumn{3}{|c|}{ Individual fluoride exposure } \\
\hline & & & & $\begin{array}{l}\text { use of } \\
\text { fluoridated } \\
\text { salt }\end{array}$ & $\begin{array}{l}\text { fluoride } \\
\text { tablets } \\
\mu \mathrm{g} / \text { day }\end{array}$ & $\begin{array}{l}\text { toothpaste fluoride } \\
\text { concentration } \\
\mu \mathrm{g} / \mathrm{g}\end{array}$ \\
\hline 1 & $\mathrm{f}$ & 6 & 23.5 & yes & 500 & 400 \\
\hline 2 & $\mathrm{f}$ & 4 & 19.5 & yes & 500 & 400 \\
\hline 3 & $\mathrm{~m}$ & 3 & 18.0 & yes & 500 & 250 \\
\hline 4 & $\mathrm{f}$ & 3 & 14.0 & yes & - & 500 \\
\hline 5 & $\mathrm{f}$ & 3 & 13.0 & yes & 500 & 1,000 \\
\hline 6 & $\mathrm{~m}$ & 5 & 21.0 & yes & - & 250 \\
\hline 7 & $\mathrm{~m}$ & 3 & 17.0 & yes & 500 & 250 \\
\hline 8 & $\mathrm{~m}$ & 3 & 13.5 & no & 250 & 400 \\
\hline 9 & $\mathrm{f}$ & 6 & 21.0 & no & 1,000 & 400 \\
\hline 10 & $\mathrm{~m}$ & 5 & 20.0 & no & 1,000 & 400 \\
\hline 11 & $\mathrm{~m}$ & 5 & 17.5 & no & 250 & - \\
\hline
\end{tabular}

Table 2. Fluoride intake from diet and toothpaste in 11 pre-school children, average of 2 consecutive days

\begin{tabular}{|c|c|c|c|c|c|}
\hline \multirow{2}{*}{$\begin{array}{l}\text { Child } \\
\text { No. }\end{array}$} & \multicolumn{4}{|c|}{ Dietary fluoride intake, $\mu \mathrm{g} /$ day } & \multirow{2}{*}{$\begin{array}{l}\text { Fluoride swallowec } \\
\text { from toothpaste } \\
\mu \mathrm{g} / \text { day }\end{array}$} \\
\hline & food $^{a}$ & beverages & $\begin{array}{l}\text { milk and dairy } \\
\text { products }\end{array}$ & $\begin{array}{l}\text { total from } \\
\text { diet }\end{array}$ & \\
\hline 1 & $27.1^{\mathrm{a}}$ & 69.7 & 42.6 & 139.4 & 140.2 \\
\hline 2 & $22.9^{a}$ & 70.5 & 70.3 & 163.7 & 366.8 \\
\hline 3 & $49.9^{a}$ & 199.2 & 7.5 & 256.6 & 350.7 \\
\hline 4 & $37.3^{\mathrm{a}}$ & 93.3 & 49.1 & 179.7 & 505.4 \\
\hline 5 & $39.7^{a}$ & 21.3 & 7.8 & 68.8 & 374.5 \\
\hline 6 & $29.2^{\mathrm{a}}$ & 126.1 & 4.1 & 159.4 & 323.3 \\
\hline 7 & $18.0^{\mathrm{a}}$ & 37.2 & 15.4 & 70.6 & 21.5 \\
\hline 8 & 16.6 & 411.4 & 25.5 & 453.5 & 361.3 \\
\hline 9 & 16.5 & 322.5 & 10.1 & 349.0 & 462.6 \\
\hline 10 & 97.6 & 41.0 & 8.1 & 146.7 & 106.8 \\
\hline 11 & 32.5 & 196.1 & 11.2 & 239.8 & 0 \\
\hline Mean & 35.2 & 144.4 & 22.9 & 202.5 & 273.9 \\
\hline SD & 23.2 & 126.5 & 21.7 & 116.2 & 175.6 \\
\hline
\end{tabular}

a Including the use of fluoridated salt. ing the following temperature-time schedule: step $1: 30 \mathrm{~min}$ at $150{ }^{\circ} \mathrm{C}$; step 2: $30 \mathrm{~min}$ at $300^{\circ} \mathrm{C}$; step 3: $30 \mathrm{~min}$ at $350{ }^{\circ} \mathrm{C}$; step 4: $150 \mathrm{~min}$ at $400^{\circ} \mathrm{C}$. The solid residue was extracted 3 times with $1 \mathrm{ml}$ distilled water per run. Two millilitres of the extract or the other liquid samples was buffered with $2 \mathrm{ml}$ total ionic strength adjustment buffer (TISAB, Merck, Darmstadt, Germany). After equilibrating the electrode for 10 min under continuous stirring in these prepared samples, the fluoride concentration (c) could be read on the ionometer. The calibration range was $20 \mu \mathrm{g} / \mathrm{l}$ to $20 \mathrm{mg} / \mathrm{l}$. The intraserial precision $\left(\mathrm{n}_{\text {sample }}=20\right)$ was $2.9 \%\left(c_{\text {mean }}=105.7 \mu \mathrm{g} / \mathrm{l}\right)$, the interserial precision (day to day, $\mathrm{n}=15)$ was $3.9 \%\left(\mathrm{c}_{\text {mean }}=105.7 \mu \mathrm{g} / \mathrm{l}\right)$. The recovery after the food ashing using mashed potatoes with added $1 \mu \mathrm{g}$ fluoride per gram weight was $98.7 \%$.

\section{Statistical Analysis}

Statistical evaluation was based on descriptive methods (means and standard deviations). Several correlation coefficients (Spearman's, Pearson's, Kendall-Tau) were used to examine the relationship between fluoride intake and excretion. To quantify it we performed a linear regression analysis. The data were analysed by SPSS for Windows, release10.0.

\section{Results}

In the present study total fluoride intake and excretion were measured in 11 pre-school children from Dresden. Their age, gender and body weight as well as individual flu- 
Table 3. Dietary fluoride intake in 11 preschool children on 2 consecutive days

\begin{tabular}{|c|c|c|c|}
\hline \multirow{2}{*}{$\begin{array}{l}\text { Child } \\
\text { No. }\end{array}$} & \multicolumn{3}{|c|}{ Dietary intake, $\mu \mathrm{g} /$ day } \\
\hline & 1st day & 2nd day & $\begin{array}{l}\text { average of } \\
\text { the } 2 \text { days }\end{array}$ \\
\hline 1 & 146.0 & 132.1 & 139.4 \\
\hline 2 & 122.4 & 204.8 & 163.7 \\
\hline 3 & 206.3 & 305.7 & 256.6 \\
\hline 4 & 202.0 & 156.6 & 179.7 \\
\hline 5 & 80.7 & 56.0 & 68.8 \\
\hline 6 & 24.3 & 294.3 & 159.4 \\
\hline 7 & 80.8 & 60.3 & 70.6 \\
\hline 8 & 419.5 & 487.5 & 453.5 \\
\hline 9 & 466.0 & 231.9 & 349.0 \\
\hline 10 & 84.1 & 209.1 & 146.7 \\
\hline 11 & 282.9 & 196.5 & 239.8 \\
\hline
\end{tabular}

oride exposure are given in table 1. Fluoridated domestic salt was used in the homes of 7 children, and 9 out of the 11 participants took fluoride tablets in variable dosages.

\section{Fluoride Intake from Food and Drink}

Table 2 shows the average daily fluoride intake ( $\mu \mathrm{g}$ F/day) from solid food, beverages and milk or dairy products for each child (unless otherwise indicated, the averages of the results from day 1 and 2 are used for the statistics). Mean fluoride intake from food and drink was $202.5 \pm 116.2 \mu \mathrm{g}$ F/day in the children studied, with drinks at $144.4 \pm 126.5 \mu \mathrm{g}$ F/day on average accounting for a major portion. Wide variations in fluoride intake were demonstrated between study days as well as between children (table 3).

\section{Fluoride Intake from Toothbrushing}

With one exception (child 11) all children used fluoridated toothpaste to brush their teeth (table 1). The daily fluoride amount swallowed from toothbrushing averaged $273.9 \pm 175.6 \mu \mathrm{g} /$ day (table 2). Apart from 1 child who swallowed only $21.5 \mu \mathrm{g}$ F/day when brushing teeth, measurements varied between 106.8 and $505.4 \mu \mathrm{g} /$ day.

\section{Total Fluoride Intake}

Table 4 shows the total of fluoride intakes ( $\mu \mathrm{g} /$ day and $\mu \mathrm{g} / \mathrm{kg}$ b.w.) as derived from all sources (dietary fluoride including fluoridated salt, fluoride swallowed from toothpaste, fluoride tablets). On average $930.7 \pm 391.5 \mu \mathrm{g} \mathrm{F}$ were ingested per day (range 482.7-1,811.6 $\mu \mathrm{g} \mathrm{F}$ ). The amount swallowed from toothpaste accounted for $29.4 \%$ of the fluoride ingested, and $21.8 \%$ represented all the food eaten including the fluoridated salt partly used to prepare that food.
The remaining $48.8 \%$ was due to the fluoride tablets. Average fluoride intake by body weight was $53.0 \pm 21.4 \mu \mathrm{g} / \mathrm{kg}$. The upper 'fluorosis threshold' of $70 \mu \mathrm{g} / \mathrm{kg} \mathrm{b}$.w. was exceeded by children 5,8 and 9 (table 4 ).

\section{Urinary Fluoride Excretion}

The volume of urine excreted over $24 \mathrm{~h}$ ranged from 400 to $1,217 \mathrm{ml}$. Fluoride concentrations in urine varied between 0.42 and $1.97 \mathrm{mg} / \mathrm{l}$. The amount of fluoride eliminated in $24 \mathrm{~h}$ was $475.6 \pm 192.1 \mu \mathrm{g} /$ day (range 181.8-803.1 $\mu \mathrm{g}$ ) (table 4).

\section{Percent Excretion of Ingested Fluoride}

Urinary excretion of the fluoride ingested averaged $51.5 \%$ $(\mathrm{CI}=$ confidence interval: $95 \%=43.1-62.0 \%)$. The lowest portion recovered was $37.1 \%$ (child 11 ), while maximum recovery was $79.8 \%$ (child 7 , table 4). Total fluoride intake correlated positively with urinary fluoride excretion (Pearson's correlation coefficient $=0.82 ; p=0.002$; Spearman's correlation coefficient $=0.81 ; \mathrm{p}=0.003$; Kendall-Tau- $\mathrm{b}=0.64 ; \mathrm{p}=$ 0.006 ; linear regression coefficient $=0.40 ; \mathrm{p}=0.002$ ).

\section{Discussion}

Compliance of the children's parents was very good. The average 24-hour urine volumes of $568 \mathrm{ml}$ (minimum 350 $\mathrm{ml}$, maximum 1,217 $\mathrm{ml}$ ) suggest that urine collections were complete. Values of $406 \mathrm{ml}$ [Villa et al., 2000] and $610 \mathrm{ml}$ [Marthaler et al., 2000] show that similar volumes for 24hour urine were collected in other investigations of preschool children.

Two weekend days were chosen for the investigations. Results may not be an exact representation of fluoride intake during weekdays, when the children will take part of their meals at nursery school. This fact notwithstanding, the weekend was chosen to ascertain complete collection of foods and drinks.

Fluoride concentration can be measured in solid samples after extraction using two different methods. One method is the diffusion method [Taves, 1968] and the other is the fluoride determination after ashing and redissolution [Taves, 1983]. With the exception of some cereal products Taves [1983] found no significant differences between the results of both methods. In our investigations we used fluoride determination after ashing. The precision and recovery are acceptable.

Evaluating the children's fluoride intake from individual sources lends itself to direct comparison with the results from other studies using the duplicate-diet approach to collect food, whereas fluoride intake is often overestimated 
Table 4. Total fluoride intake, urinary flow, urinary fluoride concentration, urinary fluoride excretion and fractional urinary fluoride excretion for 11 preschool children

\begin{tabular}{|c|c|c|c|c|c|c|}
\hline \multirow{2}{*}{$\begin{array}{l}\text { Child } \\
\text { No. }\end{array}$} & \multicolumn{2}{|c|}{ Total fluoride intake } & \multirow{2}{*}{$\begin{array}{l}\text { Urinary flow } \\
\mathrm{ml} / 24 \mathrm{~h}\end{array}$} & \multirow{2}{*}{$\begin{array}{l}\text { Urinary } \\
\text { fluoride } \\
\text { concentration } \\
\mathrm{mg} / \mathrm{l}\end{array}$} & \multirow{2}{*}{$\begin{array}{l}\text { Urinary } \\
\text { fluoride } \\
\text { excretion } \\
\mu \mathrm{g} / \text { day }\end{array}$} & \multirow{2}{*}{$\begin{array}{l}\text { Fractional } \\
\text { urinary fluoride } \\
\text { excretion } \\
\%\end{array}$} \\
\hline & $\mu \mathrm{g} / \mathrm{day}$ & $\begin{array}{l}\mu \mathrm{g} / \mathrm{kg} \\
\text { b.w. }\end{array}$ & & & & \\
\hline 1 & 779.6 & 33.2 & 511 & 0.85 & 433.5 & 55.6 \\
\hline 2 & $1,030.5$ & 52.8 & 742 & 0.66 & 489.6 & 47.5 \\
\hline 3 & $1,107.3$ & 61.5 & 1,217 & 0.66 & 803.1 & 72.5 \\
\hline 4 & 685.1 & 48.9 & 541 & 0.56 & 302.9 & 44.2 \\
\hline 5 & 943.3 & 72.6 & 400 & 0.98 & 392.0 & 41.6 \\
\hline 6 & 482.7 & 23.0 & 516 & 0.62 & 319.6 & 66.2 \\
\hline 7 & 592.1 & 34.0 & 350 & 1.35 & 472.2 & 79.8 \\
\hline 8 & $1,064.8$ & 78.9 & 661 & 0.70 & 462.5 & 43.4 \\
\hline 9 & $1,811.6$ & 86.3 & 403 & 1.97 & 793.4 & 43.8 \\
\hline 10 & $1,253.5$ & 62.7 & 472 & 1.23 & 580.9 & 46.3 \\
\hline 11 & 489.8 & 28.0 & 433 & 0.42 & 181.8 & 37.1 \\
\hline Mean & 930.7 & 53.0 & 568 & 0.91 & 475.6 & 51.5 \\
\hline SD & 391.5 & 21.4 & 244 & 0.45 & 192.1 & 11.6 \\
\hline
\end{tabular}

Table 5. Summary of reported fluoride balance studies in pre-school children

\begin{tabular}{|c|c|c|c|c|c|c|c|}
\hline Survey & $\begin{array}{l}\text { Age } \\
\text { years }\end{array}$ & $\begin{array}{l}\text { Children } \\
\mathrm{n}\end{array}$ & \multicolumn{2}{|c|}{ Fluoride intake } & $\begin{array}{l}\text { Urinary fluoride } \\
\text { excretion } \\
\mu \mathrm{g} / \text { day }\end{array}$ & $\begin{array}{l}\text { Fractional urinary } \\
\text { excretion } \\
\text { of fluoride, } \%\end{array}$ & Fluoride exposure \\
\hline Brunetti and Newbrun [1983] & $3-4$ & 10 & \multirow{2}{*}{\multicolumn{2}{|c|}{$\begin{array}{l}330 \\
1,000 \mu \mathrm{g} \\
\text { single fluoride dose }\end{array}$}} & 280 & 84.8 & ‘optimally’ FDW \\
\hline Villa et al. [1999] & $3-5$ & 48 & & & & 30.7 & DW: $0.5-0.6 \mathrm{mg} \mathrm{F} / \mathrm{l}$ \\
\hline Zohouri and Rugg-Gunn [2000] & 4 & 78 & 426 & & 339 & 80.0 & $\begin{array}{l}\text { DW: } 0.33 \mathrm{mg} \mathrm{F} / \mathrm{l} \text {; } \\
\text { vegetarian diet }\end{array}$ \\
\hline Present study & $3-6$ & 11 & 931 & 53.1 & 476 & 51.5 & $\begin{array}{l}\text { DW: } 0.25 \mathrm{mg} \mathrm{F} / \mathrm{l} \\
\text { FP: } 250-1,000 \mu \mathrm{g} / \mathrm{g} \\
\text { FT: } 250-1,000 \mu \mathrm{g} \\
\text { FS: } 250 \mathrm{mg} \mathrm{F} / \mathrm{kg}\end{array}$ \\
\hline
\end{tabular}

FP = Use of fluoridated toothpaste; FT = intake of fluoride tablets; FS = use of fluoridated table salt.

when food consumption tables are the sole basis for calculation [Guha-Chowdhury et al., 1996].

The children of this study took in an average daily amount of $203 \mu \mathrm{g}$ fluoride from solid and liquid foods. This included the fluoride dose ingested with fluoridated domestic salt. In New Zealand age peers the average daily fluoride intake from diet was found to be $150 \mu \mathrm{g}$ in an area without FDW and $360 \mu \mathrm{g}$ with optimal FDW [Guha-Chowdhury et al., 1996]. American children ingested $219 \mu \mathrm{g}$ (without FDW) or $542 \mu \mathrm{g}$ (with FDW) from foods and drinks [RojasSanchez et al., 1999]. As in our investigations, beverages accounted for the largest part of fluoride intake.
The finding that a substantial portion of total fluoride intake resulted from swallowing toothpaste was common to all studies. In the present study this portion of $274 \mu \mathrm{g} / \mathrm{day}$ (range: $0-505 \mu \mathrm{g}$ ) on average was higher than the total amount of fluoride ingested with food $(203 \mu \mathrm{g})$ and represented $29 \%$ of total intake. In the New Zealand children [Guha-Chowdhury et al., 1996] the amount swallowed from toothpaste was on average $340 \mu \mathrm{g} / \mathrm{day}$ in children without FDW and $320 \mu \mathrm{g} /$ day in children with FDW, which is presumably due to higher fluoride concentrations in the toothpaste used. In American children the percentage swallowed with toothpaste (fluoride concentration $0.10-0.11 \%$ ) ranged 
from 43 to $71 \%$ of the total intake [Rojas-Sanchez et al., 1999]. These comparisons support the concept of using low fluoride toothpaste $(0.05 \%)$ in pre-school children.

The total fluoride intake of $931 \pm 392 \mu \mathrm{g}$ determined in the children under discussion still falls short of the daily allowance of $1,100 \mu \mathrm{g}$ recommended by the German Nutrition Society [Deutsche Gesellschaft für Ernährung, 2000]. While the average fluoride intake in this study was thus $53 \mu \mathrm{g} / \mathrm{kg}$ in terms of body weight, 6 children exceeded this value and 3 of them exceeded the $70-\mu \mathrm{g} / \mathrm{kg}$ threshold. In children from New Zealand and Iran who were also living in areas with low FDW and did not receive fluoride supplementation, the mean daily fluoride intake established was 27 and $30 \mu \mathrm{g} / \mathrm{kg}$, respectively [Guha-Chowdhury et al., 1996; Zohouri and Rugg-Gunn, 2000]. If fluoride supplementation by tablets was given up, the average total fluoride intake of the children we investigated would drop from 931 to $477 \mu \mathrm{g}$. In terms of body weight this would equal an average reduction of daily fluoride intake from 53 to $25 \mu \mathrm{g} / \mathrm{kg}$, corresponding to the fluoride intake of the New Zealand and Iranian children given above. None of the children would then exceed the lower 'threshold value' for the development of dental fluorosis.

Mean urinary fluoride excretion of $476 \mu \mathrm{g}$ F/day was slightly higher than in two groups of Dresden pre-schoolers investigated in 1995/96, when 377 and $411 \mu \mathrm{g} /$ day were measured in 4-year-olds exposed only to fluoridated domestic salt at home and from canteen catering and fluoridated toothpaste [Hetzer et al., 1996]. In other investigations fluoride exposure of pre-school children via FDW and fluoridated toothpaste resulted in mean fluoride excretion rates of 420,550 or $749 \mu \mathrm{g} /$ day [Rugg-Gunn et al., 1993; Baez et al., 2000]. On the other hand urinary fluoride excretion was only $245 \mu \mathrm{g} / 24 \mathrm{~h}$ in 15 Swiss children aged 3-4 years who were consuming fluoridated salt in their homes [Marthaler et al., 2000]. On comparing the rates of urinary fluoride excretion in the literature, Baez et al. [2000] concluded that excretion rates of 400-500 $\mu \mathrm{g} / \mathrm{day}$ in children of 3-6 years could be considered an indication of 'optimal' fluoride intake.

Since measuring total fluoride intake is quite demanding in terms of cost, determining the fraction eliminated with urine may be used as a simple procedure of estimating fluoride intake. However this approach relies on relatively constant rates of urinary fluoride excretion in a given age group or growth period. While the fraction excreted should be about $50 \%$ in adults, in children the percentage should not be higher than 30-40\% [Murray et al., 1991]. The studies investigating this problem in pre-school children yielded widely varying results (table 5 ).
In 1983 Brunetti and Newbrun reported that the fluoride amount excreted with the urine and faeces had been $84.8 \%$ in children aged 3-4 years. Ekstrand et al. [1994] obtained similar results. In infants and small children aged 79-422 days, $87.5 \%$ of the fluoride ingested were eliminated via urine and faeces if the children had only been fed a formula without fluoride supplementation. The fluoride portion excreted would, however, drop to $48-53 \%$ when they were administered concurrent daily doses of $0.25 \mathrm{mg}$ of fluoride in tablet form.

By contrast, Villa et al. [1999] reported that children between the age of 3 and 5 years excreted only $30.7 \%$ of a single-challenge dose of $1 \mathrm{mg}$ F. Fluoride elimination with the faeces and sweat was not considered. When investigating children under continuous fluoride exposure Villa et al. [2000] observed that in spite of the difference in exposure again only $35.5 \%$ of the fluoride ingested was excreted with urine. For comparability with the results of Brunetti and Newbrun [1983] and Ekstrand et al. [1994] it is necessary to add the excretion rate for intestinal fluoride elimination, i. e. the fraction that its not bioavailable. Under the above conditions maximum faecal elimination of fluoride amounts to $10 \%$. Fluoride elimination with sweat is negligible.

Zohouri and Rugg-Gunn [2000] studied 4-year-old children in Iran living largely on a vegetarian diet. In these children the mean fluoride elimination rate in urine was $80 \%$. This would place our results on the rate of urinary fluoride excretion more or less halfway between $85 \%$ [Brunetti and Newbrun, 1983; Zohouri and Rugg-Gunn, 2000] and 30-35\% [Villa et al., 1999] and would permit to also apply to pre-school children the rule of thumb, which says that doubling the amount of fluoride excretion approximates fluoride intake [Murray et al., 1991].

A variety of explanations have been suggested for the wide differences found in the fluoride proportion excreted with urine. Substantial interindividual variation, for one, needs to be considered. Our own investigations established fluoride excretion rates of 37.1 and $79.7 \%$, which shows that interindividual variation may cover the complete range of $30-85 \%$ obtained in other studies. It is likely that these fluctuations would level out with increasing numbers of subjects in a sample. The divergent growth activity of the children correlates with the differences in skeletal uptake of calcium and fluoride and thus with differences in the levels of the fluoride excretion rates in urine [Zohouri and RuggGunn, 2000]. Since urinary $\mathrm{pH}$ is found to be in the alkaline range when a largely vegetarian diet is consumed, less fluoride is re-absorbed in the tubular renal section, which in turn leads to higher fluoride elimination [Whitford, 1990]. This may explain the high excretion rates in Iranian children [Zo- 
houri and Rugg-Gunn, 2000]. The diet of the German children was relatively rich in protein, which presumably results in lower fluoride excretion rates than those found in the Iranian children.

The investigations under discussion lead to the following conclusions:

(1) Total daily fluoride intake of the children studied averaged $53 \mu \mathrm{g} \mathrm{F} / \mathrm{kg}$ b.w. and was accordingly within the optimal range of intake, which is $50-70 \mu \mathrm{g} / \mathrm{kg}$ b.w. per day. This range was exceeded by 3 out of 11 children $(73,79,86$ $\mu \mathrm{g} \mathrm{F} / \mathrm{kg}$ b.w.). Discontinuing all supplementation with fluoride tablets would reduce the average total fluoride intake to $25 \mu \mathrm{g} / \mathrm{kg}$ b.w.
(2) The fluoride proportion excreted with urine was found to be $52 \%$ in this study. However earlier investigations into urinary excretion rates demonstrate high variability with rates ranging from 30 to $85 \%$. Further studies in larger populations with different backgrounds as to fluoride exposure and different dietary patterns (e.g. vegetarian) are necessary to clarify this inconsistency.

\section{Acknowledgement}

The authors would like to thank Prof. Dr. T. M. Marthaler for his helpful advice.

\section{References}

Baez RJ, Baez MX, Marthaler TM: Urinary fluoride excretion by children 4-6 years old in a south Texas community. Pan Am J Public Health 2000;7:242-247.

Birkhed D: Behavioural aspects of dietary habits and dental caries: Diet, nutrition and dental caries. Caries Res 1990;24(suppl 1):27-35.

Brunetti A, Newbrun E: Fluoride balance of children 3 and 4 years old (abstract 41). Caries Res 1983; 17:171.

Burt BA: The changing patterns of systemic fluoride intake. J Dent Res 1992;71:1228-1237.

Deutsche Gesellschaft für Ernährung, Österreichische Gesellschaft für Ernährung, Schweizerische Vereinigung für Ernährung: Referenzwerte für die Nährstoffzufuhr. Frankfurt a. M., Umschau/Braus, 2000.

Ekstrand J, Ziegler EE, Nelson SE, Fomon SJ: Absorption and retention of dietary and supplemental fluoride by infants. Adv Dent Res 1994;8:175-180.

Fomon SJ, Ekstrand J: Fluoride; in Fomon SJ (ed): Nutrition of Normal Infants. St Louis, Mosby, 1993.

Guha-Chowdhury N, Drummond BK, Smillie AC: Total fluoride intake in children aged 3 to 4 years: A longitudinal study. J Dent Res 1996; 75:1451-1457.
Hetzer G, Straube H, Neumeister V: Zur Verwendung fluoridierten Speisesalzes in der Gemeinschaftsverpflegung (The use of fluoridated salt in canteen catering). Dtsch Zahnärztl Z 1996; 51:679-682.

Marthaler TM (ed): Monitoring of Renal Fluoride Excretion in Community Preventive Programmes on Oral Health. Geneva, World Health Organisation, 1999.

Marthaler TM, Binder-Fuchs M, Baez RJ, Menghini G: Urinary fluoride excretion in Swiss children aged 3 and 4 consuming fluoridated domestic salt. Acta Med Dent Helv 2000;5: 89-97.

Marthaler TM, Steiner M, Menghini G, De Crousaz P: Urinary fluoride excretion in children with low fluoride intake or consuming fluoridated salt. Caries Res 1995;29:26-34.

Murray JJ, Rugg-Gunn AJ, Jenkins GN: Fluoride in caries prevention, ed 3. Oxford, Wright/Butterworth-Heinemann, 1991.

Rojas-Sanchez F, Kelly SA, Drake KM, Eckert GJ, Stookey GK, Dunipace AJ: Fluoride intake from foods, beverages and dentifrice by young children in communities with negligibly and optimally fluoridated water: A pilot study. Community Dent Oral Epidemiol 1999;27: 288-297.

Rugg-Gunn AJ, Nunn JH, Ekanayake L, Saparamadu KDG, Wright WG: Urinary fluoride excretion in 4-year-old children in Sri Lanka and England. Caries Res 1993;27:478-483.
Taves DR: Separation of fluoride by rapid diffusion using hexamethyldisiloxane. Talanta 1968;15:969-974.

Taves DR: Dietary intake of fluoride ashed (total fluoride) v. unashed (inorganic fluoride) analysis of individual foods. Br J Nutr 1983;49:295301.

Villa A, Anabalón M, Cabezas L: The fractional urinary fluoride excretion in young children under stable fluoride intake conditions. Community Dent Oral Epidemiol 2000;28:344355.

Villa A, Salazar G, Anabalón M, Cabezas L: Estimation of the fraction of an ingested dose of fluoride excreted through urine in pre-school children. Community Dent Oral Epidemiol 1999;27:305-312.

Whitford GM: The physiological and toxicological characteristics of fluoride. J Dent Res 1990;69:539-549.

Whitford GM, Allmann DW, Shahed AR: Topical fluorides: Effect on physiological and biochemical processes. J Dent Res 1987;66: 1072-1078.

Zohouri FV, Rugg-Gunn AJ: Total fluoride intake and urinary excretion in 4-year-old Iranian children residing in low-fluoride areas. $\mathrm{Br} \mathrm{J}$ Nutr 2000;83:15-25. 